\title{
Critical analysis of the potential of targeting GPC3 in hepatocellular carcinoma
}

\author{
This article was published in the following Dove Press journal: \\ Journal of Hepatocellular Carcinoma \\ 2I May 2014 \\ Number of times this article has been viewed
}

\author{
Kazuya Ofuji \\ Keigo Saito \\ Toshiaki Yoshikawa \\ Tetsuya Nakatsura \\ Division of Cancer Immunotherapy, \\ Exploratory Oncology Research and \\ Clinical Trial Center, National Cancer \\ Center, Kashiwa, Japan
}

\begin{abstract}
Hepatocellular carcinoma (HCC) is a leading cause of cancer-related deaths worldwide. The treatment options for patients with advanced HCC are limited, and novel treatment strategies are required urgently. Glypican-3 (GPC3), a member of the glypican family of heparan sulfate proteoglycans, is overexpressed in $72 \%-81 \%$ of $\mathrm{HCC}$ cases, and is correlated with a poor prognosis. GPC3 regulates both stimulatory and inhibitory signals, and plays a key role in regulating cancer cell growth. GPC3 is released into the serum, and so might be a useful diagnostic marker for HCC. GPC3 is also used as an immunotherapeutic target in HCC. A Phase I study of a humanized anti-GPC3 monoclonal antibody, GC33, revealed a good safety profile and potential antitumor activity, and a Phase II trial is currently ongoing. In addition, the authors' investigator-initiated Phase I study of a GPC3-derived peptide vaccine showed good safety and tolerability, and demonstrated that the GPC3 peptide-specific cytotoxic T-lymphocyte frequency in peripheral blood correlated with overall survival in HCC patients. A sponsor-initiated Phase I clinical trial of a three-peptide cocktail vaccine, which includes a GPC3-derived peptide, is also underway. GPC3 is currently recognized as a promising therapeutic target and diagnostic marker for HCC. This review introduces the recent progress in GPC3 research, from biology to clinical impact.
\end{abstract}

Keywords: GPC3, hepatocellular carcinoma, immunotherapy

\section{Introduction}

Hepatocellular carcinoma (HCC) is the third leading cause of cancer-related deaths worldwide. ${ }^{1}$ HCC patients are often diagnosed at an advanced stage, and so the prognosis is often poor. Currently, surgery or locally ablative treatments such as percutaneous ethanol injection or radiofrequency ablation are the standard treatments for early-stage HCC. However, these treatments are no longer available and options are limited for most patients with advanced HCC. ${ }^{2}$ Generally, transarterial chemoembolization or systemic chemotherapy is used. However, these therapeutic approaches are not curative in most patients. Sorafenib, a multi-targeted tyrosine kinase inhibitor, is the only drug that has significantly prolonged the survival of patients with advanced HCC; $;, 4$ therefore, it has become the standard agent for first-line systemic treatment. However, the incidence of adverse effects is high, and there are no effective secondline treatments for patients who do not respond to sorafenib. Therefore, new treatment strategies for patients with advanced HCC should be established.

To date, several immunotherapeutic clinical trials in patients with advanced HCC have been performed. These studies have shown feasibility and safety, but no dramatic clinical responses. ${ }^{5,6}$ Nevertheless, some randomized controlled trials have shown the
Correspondence: Tetsuya Nakatsura Division of Cancer Immunotherapy, Exploratory Oncology Research and Clinical Trial Center, National Cancer Center, 6-5-I Kashiwanoha,

Kashiwa 277-8577, Japan

$\mathrm{Tel}+8|47| 3 \mid 5490$

Fax +81471336606

Email tnakatsu@east.ncc.go.jp 
potential to reduce the risk of cancer recurrence in adjuvant settings. ${ }^{6}$ Therefore, an immunotherapeutic approach is potentially an attractive treatment option for HCC.

Various tumor antigens for HCC have been identified and investigated as immunotherapeutic targets. ${ }^{7}$ GPC 3 is a member of the glypican family of heparan sulfate proteoglycans that are attached to the cell surface via glycosylphosphatidylinositol (GPI) anchors. ${ }^{8}$ Mutations in GPC3 cause Simpson-Golabi-Behmel syndrome, ${ }^{9}$ which is an X-linked disorder characterized by pre- and postnatal overgrowth with visceral and skeletal anomalies. GPC3-deficient mice exhibited similar characteristics as Simpson-Golabi-Behmel syndrome patients. ${ }^{10}$ GPC3 is overexpressed in $72 \%-81 \%$ of patients with HCC. ${ }^{11-15}$ Therefore, GPC3 has been recognized as a potential immunotherapeutic target or diagnostic marker for HCC. This paper reviews the biology of GPC3 and discusses recent advances in GPC3-targeted HCC immunotherapy.

\section{Tumor-associated antigens (TAAs) in HCC}

TAA-specific immunotherapy is an attractive strategy because it is associated with fewer adverse events. Therefore, identifying appropriate TAAs is important for the development of TAA-specific cancer immunotherapies. Boon et al initially reported that MAGE-A was a human TAA in a melanoma patient, and that the human immune system could recognize TAA expressing-cancer cells as foreign bodies and exclude them. ${ }^{16}$ Subsequently, a novel approach termed serological analysis of recombinant complementary DNA expression libraries (SEREX) was developed to identify TAAs. ${ }^{17,18}$ Complementary DNA microarray technology is also useful for identifying novel cancer-associated genes and for classifying human cancers at the molecular level. ${ }^{19,20}$ In HCC, some TAAs, such as AFP, MAGE-A, NY-ESO-1, SSX2, and telomerase reverse transcriptase, have been identified. ${ }^{7}$ Although GPC3 is overexpressed in HCC, ${ }^{11-15}$ it is not expressed in most normal adult tissues. Furthermore, GPC3-expression was correlated with poor prognosis in patients with $\mathrm{HCC}$ : GPC3-positive HCC patients had a significantly lower 5-year survival rate than GPC3-negative individuals $(54.5 \%$ versus $87.7 \% ; P=0.031) .{ }^{15}$ These results suggest that GPC3 might be a promising target for cancer immunotherapy.

\section{Biological aspects of GPC3 General considerations}

Glypicans are a family of heparan sulfate proteoglycans. To date, six glypicans have been identified (GPC1 to GPC6) in mammals, and two orthologs of the mammalian genes were identified in Drosophila melanogaster (Dally- and Dally-like). ${ }^{8,21}$ Glypicans of all species are classified into two subfamilies according to their sequence homology. ${ }^{21} \mathrm{In}$ general, the function of glypicans is to regulate morphogenesis during embryonic development, ${ }^{22}$ and mutations cause the overgrowth genetic disease Simpson-Golabi-Behmel syndrome. ${ }^{23}$ Several recent studies have revealed that GPC3 is overexpressed in many cancers.

\section{Structure and function of GPC3}

GPC3 is a 580 -amino acid protein $(\sim 60 \mathrm{kDa})$ that is encoded by nine exons on chromosome X (Xq26). Alternative splicing results in four variants that were isolated from the HepG2 cell line. Fourteen cysteine residues located in the core region are well conserved among glypicans, and contribute to the formation of a unique ternary structure via disulfide bonds. The amino-terminus contains a signal peptide sequence (residues 1-24), which is required for targeting to the cell surface. The carboxyl-terminus contains a hydrophobic region that is associated with the lipid bilayer of the Golgi apparatus. During the transport of GPC3 to the cell surface, the hydrophobic region is truncated by transamidase, and then covalently attached to a GPI anchor via the C-terminus of serine $560 .{ }^{24}$ Therefore, the attachment of a GPI anchor is a key post-translational modification that regulates the cellular localization of GPC3.

GPC3 regulates both stimulatory and inhibitory signals through the binding of heparan sulfate chains to signaling molecules such as Wnt, Hedgehog, fibroblast growth factors, bone morphogenetic proteins. ${ }^{25-31}$ The core protein also plays an important role for regulating the activity in Wnt and Hedgehog signaling..$^{27,28,32}$ Structural information regarding GPC3 is needed to understand these signaling mechanisms, but the three-dimensional structure of GPC3 is yet to be elucidated. Nevertheless, the crystal structure of Drosophila Dlp, an ortholog of the mammalian gene, is available. ${ }^{33}$ Structural analysis of the Dlp core region revealed an elongated conformation with $\alpha$-helix packing: this is a unique structure when compared with other proteins. Further structural studies of glypicans are necessary to understand their complex and multifunctional signaling pathways and their regulation of cancer cell growth.

\section{GPC3 biology and disease}

GPC3 is expressed in many embryonic tissues in addition to fetal liver and placenta. ${ }^{34}$ The overexpression of GPC 3 is observed in liver cancer, ovarian cancer, lung cancer, malig- 
nant melanoma, and embryonal cancers such as neuroblastoma medulloblastoma and Wilms' tumor. ${ }^{35-41}$ Capurro et al demonstrated that the binding of GPC3 to Wnt and Hedgehog activates signaling pathways that promote the growth of $\mathrm{HCC}$ cells. ${ }^{27,28}$ Moreover, the knockdown of GPC3 using small interfering RNA and subsequent gene expression analysis revealed that suppressing GPC3 inhibited the transforming growth factor- $\beta$ (TGF- $\beta$ ) receptor pathway and the subsequent growth of HCC cell lines. ${ }^{42}$ These suggest that GPC3 is an important target for cancer therapy. ${ }^{43,44}$

It is noteworthy that GPC is a novel serological cancer marker. ${ }^{12,45,46}$ Secreted circulating GPC3 is detected in the blood of cancer patients with $\mathrm{HCC}^{11,45}$ and melanoma, ${ }^{37.47}$ and the presence of soluble GPC3 correlates with cancer progression. However, because GPC3 is initially membrane-bound via a GPI anchor, it is currently unknown how GPC3 is secreted into the circulation. It was reported that GPC3 can be cleaved by Notum ( $\alpha / \beta$-hydrolase enzyme) and furin-like convertase, ${ }^{48,49}$ releasing the N-terminal domain and fulllength GPC3 from the cell surface. ${ }^{50,51}$ Secreted GPC3 might be useful for cancer diagnosis.

\section{GPC3 as a diagnostic marker for HCC GPC3 expression in $\mathrm{HCC}$ at the messenger RNA or protein level}

Several studies have suggested that GPC3 is a potential therapeutic target in liver cancer because it is overexpressed in HCC, but is not expressed or is expressed at only low levels in normal adult tissue. ${ }^{52-54} \mathrm{Hsu}$ et al performed pioneering work to identify GPC3 as a potential biomarker for HCC. ${ }^{55}$ When GPC3 was compared with AFP, another established HCC marker, data revealed higher GPC3 messenger RNA expression compared with serum $\alpha$-fetoprotein (AFP), levels (71.7\% versus $51.3 \%$ ) based on the analysis of 113 patients with unicentric primary HCC. The authors also reported previously that GPC3 is specifically overexpressed in $\mathrm{HCC}$ by analyzing complementary DNA microarrays containing 23,040 genes. The expression profiles of $20 \mathrm{HCC}$ samples, corresponding noncancerous liver tissues, and various normal human tissues revealed that GPC3 was overexpressed specifically in HCC. ${ }^{11}$

Capurro et al confirmed increased GPC3 expression in HCC patients using a mouse monoclonal antibody (1G12) against a GPC3 C-terminal peptide. ${ }^{12}$ Immunohistochemistry revealed that GPC3 was overexpressed in $72 \%$ of $\mathrm{HCC}$ samples. Therefore, GPC3 might also be useful as an ancillary tool during histopathological diagnostic processes to distinguish HCC from cirrhosis, dysplastic nodules, and focal nodular hyperplasia-like nodules. ${ }^{56}$

\section{GPC3 as a serum marker for HCC}

Several studies have been performed to validate the diagnostic potential of GPC3 as a serum marker by developing methodologies such as enzyme-linked immunosorbent assays and radioimmunoassays. ${ }^{45,57}$ Several antibody-based immunoassays have been developed to assess potential serum biomarkers. Using multiple serum markers, including AFP and protein induced by vitamin $\mathrm{K}$ absence or antagonists-II (PIVKA-II), might increase diagnostic accuracy. Although GPC3 is a cellsurface marker, it can be released into the serum by the lipase Notum, which cleaves the GPI anchor. ${ }^{49}$ Specifically, Hippo et al reported that GPC3 is cleaved between Arg358 and Ser359, and that the N-terminal fragment of GPC3 is also released into circulation. They reported the usefulness of the N-terminal fragment of GPC3 for diagnosing early-stage HCC. ${ }^{51}$ Therefore, GPC3 also exhibits diagnostic value as a serum marker. ${ }^{57,58}$ Qiao et al compared the serum levels of three markers (GPC3, human cervical cancer oncogene [HCCR], and AFP) for diagnosing HCC in 189 patients (101 HCC, 40 cirrhosis, and 18 hepatitis cases and 30 healthy control donors). They reported that GPC 3 was the most accurate diagnostic marker: using a cutoff of 26.8 $\mathrm{ng} / \mathrm{mL}$ for the diagnosis of HCC, GPC3 had a sensitivity of $51.5 \%$ and a specificity of $92.8 \%$. In addition, the simultaneous detection of three markers increased the sensitivity significantly to $80.2 \%$ higher than AFP alone. ${ }^{58}$ In a meta-analysis comparing AFP and GPC3 as serum markers for HCC, the pooled sensitivities for AFP and GPC 3 were $51.9 \%$ and $59.2 \%$, and the pooled specificities were $94 \%$ and $84.8 \%$, respectively. ${ }^{59}$ This suggests that GPC3 and AFP are comparable serum markers. Serum GPC3 might be a useful tumor marker in patients with HCC. However, the biochemistry of serum GPC3 is yet to be elucidated, and so further studies are needed.

\section{GPC3 as an immunotherapeutic target in HCC Identification of human leukocyte antigen (HLA)-A2- or A24-restricted GPC3- derived epitope peptides}

Identifying TAA-derived epitope peptides is the first step in the development of peptide vaccines. HLA-A24 is the most common HLA class I allele in the Japanese population (60\%) ${ }^{60,61}$ Structural motifs of peptides bound to human HLA-A24 and BALB/c mouse H-2K ${ }^{\mathrm{d}}$ are similar, ${ }^{62,63}$ and the amino acid sequences of human and mouse GPC 3 have $95 \%$ homology. These studies identified the mouse GPC3-derived 
and $\mathrm{K}^{\mathrm{d}}$ - restricted cytotoxic T-lymphocyte (CTL) epitope peptide GPC $3_{298-306}$ (EYILSLEEL) in BALB/c mice. This peptide-specific CTL showed specific cytotoxicity against GPC3-expressing or peptide-pulsed cancer cell lines, suggesting that GPC3 was highly immunogenic and could elicit effective antitumor immunity in mice. Importantly, there was no evidence of autoimmune reactions in the treated mice. ${ }^{64}$ Because of the similarities in the peptide binding motifs between $\mathrm{H}-2 \mathrm{~K}^{\mathrm{d}}$ and HLA-A24, this peptide was applicable for immunotherapy in HLA-A24-positive patients.

$H L A-A 2$ is also expressed in $40 \%$ of Japanese individuals, as well as other ethnic populations. ${ }^{60,65}$ An HLA-A2restricted GPC $3_{144-152}$ (FVGEFFTDV) peptide was also identified using $H L A-A 2.1$ transgenic mice. ${ }^{58} \mathrm{~A}$ binding assay was performed, and it was reported that the HLA-A*02:01restricted GPC $3_{144-152}$ (FVGEFFTDV) peptide could bind to HLA-A*02:06 and HLA-A*02:07. This suggests that HLAA2-restricted GPC $3_{144-152}$ (FVGEFFTDV) might be effective in HLA-A*02:06 and HLA-A*02:07 patients.

These GPC3-derived peptide-specific CTLs could be induced from the peripheral blood mononuclear cells of HCC patients by in vitro stimulation with peptide. The adoptive transfer of these GPC3-derived peptide-specific CTLs reduced the mass of human HCC tumors implanted into nonobese diabetic/severe combined immunodeficiency mice. ${ }^{66}$

\section{GPC3-targeted vaccine therapy}

The authors recently completed an investigator-initiated Phase I clinical trial of GPC3-derived peptide vaccines to evaluate their safety, tolerability, and efficacy in patients with advanced HCC. ${ }^{67}$ Thirty-three advanced HCC patients were enrolled and received escalating doses of GPC3-derived peptide vaccine $(0.3,1.0,3.0,10$, and $30 \mathrm{mg} /$ patient). On days 1,15 , and 29 , peptides were administered in liquid form, emulsified with incomplete Freund's adjuvant by intradermal injection. GPC $_{298-306}$ (EYILSLEEL) peptide was used in 17 HLA-A24positive patients, and GPC $3_{144-152}$ (FVGEFFTDV) peptide was used in 16 HLA-A2-positive patients.

Dose-limiting toxicity and dose-specific adverse events were not seen, and GPC3-derived peptide vaccine treatment was well tolerated. One of the thirty-three patients was judged to have a partial response, whereas 19 patients exhibited stable disease after 2 months according to Response Evaluation Criteria In Solid Tumors (RECIST). ${ }^{68}$ The disease control rate (partial response plus stable disease) was $60.6 \%$ after 2 months. The median time to tumor progression was 3.4 months (95\% confidence interval [CI] 2.1-4.6), and the median overall survival was 9.0 months $(95 \%$ CI $8.0-10.0)$.
Immunologically, the frequency of GPC3-peptide-specific CTL in the peripheral blood correlated with the overall survival of HCC patients. In the multivariate analysis, GPC3 peptide-specific CTL frequency was a predictive factor for overall survival. The median overall survival of all 33 patients was 12.2 months (95\% CI 6.5-18.0) in patients with a high frequency of GPC3-specific CTLs compared with 8.5 months (95\% CI 3.7-13.1) in individuals with a low frequency $(P=0.033)$. Moreover, the infiltration of cluster of differentiation (CD)8-positive T-cells into HCC cells was confirmed.

Based on this Phase I study, a Phase II study of the GPC3-derived peptide vaccine is ongoing in an adjuvant setting (UMIN-CTR: 000002614). Forty-four patients with HCC who had undergone surgery or radiofrequency ablation were enrolled. The primary end points of this study were the 1- and 2-year recurrence rates, and the secondary end point was the immunological response. Patient enrollment has been completed, and the study is ongoing. An additional sponsor-initiated Phase I clinical trial of a three-peptide cocktail vaccine, which includes a GPC3-derived peptide, is also underway.

\section{Anti-GPC3 antibody therapy}

GPC3 has been suggested as a potential target for antibodybased therapy in liver cancer because of its high-level expression in HCC. The murine monoclonal antibody GC33, which binds specifically to the C-terminal region of GPC3 with a high affinity, caused significant antibody-dependent cellular cytotoxicity against $\mathrm{HCC}$ cells, and exhibited potent antitumor activity in xenograft models. ${ }^{69-72}$ For the clinical application of GC33, a humanized GC33 was generated using complementarity-determining region grafting with the aid of both the hybrid variable region and two-step design methods. To improve the stability of the humanized GC33, it was further optimized by replacing the amino acid residues that might affect the structure of the variable region of its heavy chain. ${ }^{73}$

Because of these preclinical data highlighting the relevance of GPC3 as a potential therapeutic target in HCC, a first-in-man Phase I clinical trial to assess the safety, tolerability, and pharmacokinetics of GC33 in patients with advanced $\mathrm{HCC}$ was performed. ${ }^{74} \mathrm{~A}$ total of 20 patients were enrolled, and were assigned to receive $\mathrm{GC} 33$ at one of four sequentially increasing dose levels $(2.5,5,10$, and $20 \mathrm{mg} / \mathrm{kg}$ ) weekly by intravenous infusion. The tumor expression of GPC3 was examined in biopsied specimens using immunohistochemical staining. A total of $56 \%$ of the patients had a high total GPC3-staining score. This study provided the 
initial clinical data regarding the safety profile and pharmacokinetic features of GC33, and revealed potential antitumor activity that might be associated with the expression of GPC3 in tumors. Stable disease was seen in four patients, all of whom exhibited high GPC3 expression. The median time to progression was significantly longer in patients with tumors expressing high levels of GPC3 than in patients with low GPC3 expression.

GC33 is now being assessed in Phase II clinical trials in second-line HCC patients who have progressed after one line of systemic therapy and whose tumors exhibit positive GPC3 immunohistochemical staining (NCT01507168). Additional antibodies that target GPC3 for HCC treatment, human (MDX-1414 and HN3) and humanized mouse (YP7) antibodies, are at different stages of preclinical development. ${ }^{75}$ These trials will define the potential of GPC3 as a novel antibody therapy.

\section{Potential of GPC3 for other cancers}

GPC3 is also overexpressed in other malignant tumors, such as melanoma, Wilms' tumor, hepatoblastoma, yolk sac tumor, ovarian clear-cell carcinoma (CCC), and lung squamous cell carcinoma. ${ }^{37-41}$ However, Kim et al reported that GPC3 is downregulated in lung cancer. Thus, the overexpression of GPC3 in lung cancer is controversial. ${ }^{76}$ GPC3 has been investigated in some of these tumors as a potential immunotherapeutic target or diagnostic marker.

\section{Melanoma}

GPC3 messenger RNA and protein was identified in $>80 \%$ of melanoma and melanocytic nevus patients. ${ }^{39}$ In the authors' previous study, GPC3 protein was detected in the sera of $39.6 \%$ melanoma patients, but not in healthy donors. The positive detection of serum GPC3 was significantly higher than that of 5-S-cysteinyldopa and melanoma-inhibitory activity, both of which are well-known tumor markers for melanoma. Surprisingly, GPC 3 could be detected even in patients with stage 0 in situ melanoma. ${ }^{37}$ The combination of secreted protein acidic and rich in cysteine (SPARC) and GPC3 was also a useful tumor marker for melanoma: $66.2 \%$ of melanoma patients at stages 0 -II exhibited positive SPARC or GPC3 expression. ${ }^{47}$ This suggests that GPC3 is a novel tumor marker that is useful for the diagnosis of melanoma, particularly during the early stages.

\section{Ovarian carcinoma}

Ovarian CCC is the second most common epithelial ovarian carcinoma subtype in Japan. Ovarian CCC is associated with a poor prognosis and increased chemoresistance compared with other epithelial ovarian carcinoma subtypes. ${ }^{77,78}$ GPC3 was expressed in $\sim 40 \%$ of CCC patients, and there was a tendency toward poor progression-free survival in GPC3positive patients at stage I. ${ }^{79}$ GPC3 expression was responsible for CTL recognition, and subtoxic dose chemotherapy made tumor cells more susceptible to the cytotoxic effects of CTL. ${ }^{80} \mathrm{~A}$ Phase II trial of a GPC3-derived peptide vaccine in ovarian CCC patients is ongoing (UMIN-CTR: 000003696), and some chemotherapy-refractory ovarian CCC patients have achieved a significant clinical response. ${ }^{81}$

\section{Pediatric tumors}

A Phase I trial using a GPC3-derived peptide vaccine for pediatric patients with hepatoblastoma, nephroblastoma, or yolk sac tumors is ongoing (UMIN-CTR: 000006357). The safety and optimal dose of GPC3 peptide vaccines for pediatric cancer patients has not yet been reported.

\section{Conclusion}

Although immunotherapy is a potentially attractive treatment modality, its antitumor effects in advanced HCC are not dramatic. GPC3 is overexpressed in HCC but its expression in most adult normal tissues is low. GPC3 expression is correlated with poor prognosis in $\mathrm{HCC}$, suggesting it to be an ideal tumor antigen. GPC3 is thought to play a role in regulating cancer cell growth, although our structural and biological knowledge of GPC3 remain limited. Recent studies have shown the utility of GPC3 as a serum and immunohistochemical marker for the diagnosis of HCC. In addition, although studies assessing GPC3-targeted immunotherapies against HCC (such as vaccine and antibody therapies) have shown good safety and tolerability, sufficient clinical effects have not yet been observed. Further analysis and knowledge of GPC3 biology and its potential as an immunotherapeutic target are needed to allow the development of more effective GPC3-targeted cancer therapies. Although current GPC3targeted immunotherapies for HCC are in the preclinical and clinical trial phases of development, they are expected to yield clinical success in the near future.

\section{Acknowledgments}

This study was supported in part by Health and Labor Science Research Grants for Clinical Research and Third Term Comprehensive Control Research for Cancer from the Ministry of Health, Labor, and Welfare, Japan and the National Cancer Center Research and Development Fund (25-A-7). 


\section{Disclosure}

TN is a scientific advisor for Ono Pharmaceutical Co, Ltd. The other authors report no conflicts of interest in this work.

\section{References}

1. Schutte K, Bornschein J, Malfertheiner P. Hepatocellular carcinoma epidemiological trends and risk factors. Dig Dis. 2009;27(2):80-92.

2. Llovet JM, Burroughs A, Bruix J. Hepatocellular carcinoma. Lancet. 2003;362(9399):1907-1917.

3. Llovet JM, Ricci S, Mazzaferro V, et al. Sorafenib in advanced hepatocellular carcinoma. $N$ Engl J Med. 2008;359(4):378-390.

4. Cheng AL, Guan Z, Chen Z, et al. Efficacy and safety of sorafenib in patients with advanced hepatocellular carcinoma according to baseline status: subset analyses of the Phase III sorafenib Asia-Pacific trial. Eur J Cancer. 2012;48(10):1452-1465.

5. Greten TF, Manns MP, Korangy F. Immunotherapy of hepatocellular carcinoma. J Hepatol. 2006;45(6):868-878.

6. Sawada Y, Ofuji K, Sakai M, Nakatsura T. Immunotherapy for hepatocellular carcinoma: current status and future perspectives. In: Reeves $\mathrm{H}$, Manas DM, Lochan R, editors. Liver Tumors - Epidemiology, Diagnosis, Prevention, and Treatment. Rijeka: InTech; 2013:59-89.

7. Breous E, Thimme R. Potential of immunotherapy for hepatocellular carcinoma. J Hepatol. 2011;54(4):830-834.

8. Filmus J, Selleck SB. Glypicans: proteoglycans with a surprise. J Clin Invest. 2001;108(4):497-501.

9. Pilia G, Hughes-Benzie RM, MacKenzie A, et al. Mutations in GPC3, a glypican gene, cause the Simpson-Golabi-Behmel overgrowth syndrome. Nat Genet. 1996;12(3):241-247.

10. Cano-Gauci DF, Song HH, Yang H, et al. Glypican-3-deficient mice exhibit developmental overgrowth and some of the abnormalities typical of Simpson-Golabi-Behmel syndrome. J Cell Biol. 1999;146(1): 255-264.

11. Nakatsura T, Yoshitake Y, Senju S, et al. Glypican-3, overexpressed specifically in human hepatocellular carcinoma, is a novel tumor marker. Biochem Biophys Res Commun. 2003;306(1):16-25.

12. Capurro M, Wanless IR, Sherman M, et al. Glypican-3: a novel serum and histochemical marker for hepatocellular carcinoma. Gastroenterology. 2003;125(1):89-97.

13. Nakatsura T, Nishimura Y. Usefulness of the novel oncofetal antigen glypican-3 for diagnosis of hepatocellular carcinoma and melanoma. BioDrugs. 2005;19(2):71-77.

14. Shirakawa H, Kuronuma T, Nishimura Y, et al. Glypican-3 is a useful diagnostic marker for a component of hepatocellular carcinoma in human liver cancer. Int J Oncol. 2009;34(3):649-656.

15. Shirakawa H, Suzuki H, Shimomura M, et al. Glypican-3 expression is correlated with poor prognosis in hepatocellular carcinoma. Cancer Sci. 2009;100(8):1403-1407.

16. van der Bruggen $\mathrm{P}$, Traversari $\mathrm{C}$, Chomez $\mathrm{P}$, et al. A gene encoding an antigen recognized by cytolytic $\mathrm{T}$ lymphocytes on a human melanoma. Science. 1991;254(5038):1643-1647.

17. Park S, Lim Y, Lee D, et al. Identification and characterization of a novel cancer/testis antigen gene CAGE-1. Biochim Biophys Acta. 2003;1625(2):173-182.

18. Jager E, Chen YT, Drijfhout JW, et al. Simultaneous humoral and cellular immune response against cancer-testis antigen NY-ESO-1: definition of human histocompatibility leukocyte antigen (HLA)-A2binding peptide epitopes. J Exp Med. 1998;187(2):265-270.

19. Hasegawa S, Furukawa Y, Li M, et al. Genome-wide analysis of gene expression in intestinal-type gastric cancers using a complementary DNA microarray representing 23,040 genes. Cancer Res. 2002;62(23): 7012-7017.

20. Zembutsu H, Ohnishi Y, Tsunoda T, et al. Genome-wide cDNA microarray screening to correlate gene expression profiles with sensitivity of 85 human cancer xenografts to anticancer drugs. Cancer Res. 2002;62(2):518-527.
21. Filmus J, Capurro M, Rast J. Glypicans. Genome Biol. 2008; 9(5):224.

22. Dwivedi PP, Grose RH, Filmus J, et al. Regulation of bone morphogenetic protein signalling and cranial osteogenesis by $\mathrm{Gpc} 1$ and $\mathrm{Gpc} 3$. Bone. 2013;55(2):367-376.

23. Capurro MI, Li F, Filmus J. Overgrowth of a mouse model of SimpsonGolabi-Behmel syndrome is partly mediated by Indian hedgehog. EMBO Rep. 2009;10(8):901-907.

24. Filmus J, Shi W, Wong ZM, Wong MJ. Identification of a new membrane-bound heparan sulphate proteoglycan. Biochem $J$. 1995;311(Pt 2):561-565.

25. Capurro M, Martin T, Shi W, Filmus J. Glypican-3 binds to Frizzled and plays a direct role in the stimulation of canonical Wnt signaling. J Cell Sci. 2014;127(Pt 7):1565-1575.

26. Capurro MI, Shi W, Filmus J. LRP1 mediates Hedgehog-induced endocytosis of the GPC3-Hedgehog complex. J Cell Sci. 2012; 125(Pt 14):3380-3389.

27. Capurro MI, Xiang YY, Lobe C, Filmus J. Glypican-3 promotes the growth of hepatocellular carcinoma by stimulating canonical Wnt signaling. Cancer Res. 2005;65(14):6245-6254.

28. Capurro MI, Xu P, Shi W, Li F, Jia A, Filmus J. Glypican-3 inhibits Hedgehog signaling during development by competing with patched for Hedgehog binding. Dev Cell. 2008;14(5):700-711.

29. Filmus J, Capurro M. The role of glypicans in Hedgehog signaling. Matrix Biol. Epub January 8, 2014.

30. Midorikawa $Y$, Ishikawa S, Iwanari H, et al. Glypican-3, overexpressed in hepatocellular carcinoma, modulates FGF2 and BMP-7 signaling. Int J Cancer. 2003;103(4):455-465.

31. Filmus J. Glypicans in growth control and cancer. Glycobiology. 2001;11(3):19R-23R.

32. Williams EH, Pappano WN, Saunders AM, Kim MS, Leahy DJ, Beachy PA. Dally-like core protein and its mammalian homologues mediate stimulatory and inhibitory effects on Hedgehog signal response. Proc Natl Acad Sci U S A. 2010;107(13):5869-5874.

33. Kim MS, Saunders AM, Hamaoka BY, Beachy PA, Leahy DJ. Structure of the protein core of the glypican Dally-like and localization of a region important for Hedgehog signaling. Proc Natl Acad Sci U S A. 2011;108(32):13112-13117.

34. Pellegrini M, Pilia G, Pantano S, et al. GPC3 expression correlates with the phenotype of the Simpson-Golabi-Behmel syndrome. Dev Dyn. 1998;213(4):431-439.

35. Luo JH, Ren B, Keryanov S, et al. Transcriptomic and genomic analysis of human hepatocellular carcinomas and hepatoblastomas. Hepatology. 2006;44(4):1012-1024.

36. Zynger DL, Gupta A, Luan C, Chou PM, Yang GY, Yang XJ. Expression of glypican 3 in hepatoblastoma: an immunohistochemical study of 65 cases. Human Pathology. 2008;39(2):224-230.

37. Nakatsura T, Kageshita T, Ito $S$, et al. Identification of glypican-3 as a novel tumor marker for melanoma. Clin Cancer Res. 2004;10(19): $6612-6621$

38. Saikali Z, Sinnett D. Expression of glypican 3 (GPC3) in embryonal tumors. Int J Cancer. 2000;89(5):418-422.

39. Toretsky JA, Zitomersky NL, Eskenazi AE, et al. Glypican-3 expression in Wilms tumor and hepatoblastoma. $J$ Pediatr Hematol Oncol. 2001;23(8):496-499.

40. Maeda D, Ota S, Takazawa Y, et al. Glypican-3 expression in clear cell adenocarcinoma of the ovary. Mod Pathol. 2009;22(6): 824-832.

41. Aviel-Ronen S, Lau SK, Pintilie M, et al. Glypican-3 is overexpressed in lung squamous cell carcinoma, but not in adenocarcinoma. Mod Pathol. 2008;21(7):817-825.

42. Sun CK, Chua MS, He J, So SK. Suppression of glypican 3 inhibits growth of hepatocellular carcinoma cells through up-regulation of TGF-32. Neoplasia. 2011;13(8):735-747.

43. Allegretta M, Filmus J. Therapeutic potential of targeting glypican-3 in hepatocellular carcinoma. Anticancer Agents Med Chem. 2011;11(6): $543-548$. 
44. Filmus J, Capurro M. Glypican-3: a marker and a therapeutic target in hepatocellular carcinoma. FEBS J. 2013;280(10):2471-2476.

45. Capurro M, Filmus J. Glypican-3 as a serum marker for hepatocellular carcinoma. Cancer Res. 2005;65(1):372; author reply 372-373.

46. Yamauchi N, Watanabe A, Hishinuma M, et al. The glypican 3 oncofetal protein is a promising diagnostic marker for hepatocellular carcinoma. Mod Pathol. 2005;18(12):1591-1598.

47. Ikuta Y, Nakatsura T, Kageshita T, et al. Highly sensitive detection of melanoma at an early stage based on the increased serum secreted protein acidic and rich in cysteine and glypican-3 levels. Clin Cancer Res. 2005;11(22):8079-8088.

48. Capurro MI, Shi W, Sandal S, Filmus J. Processing by convertases is not required for glypican-3-induced stimulation of hepatocellular carcinoma growth. J Biol Chem. 2005;280(50):41201-41206.

49. Traister A, Shi W, Filmus J. Mammalian Notum induces the release of glypicans and other GPI-anchored proteins from the cell surface. Biochem J. 2008;410(3):503-511.

50. De Cat B, Muyldermans SY, Coomans C, et al. Processing by proprotein convertases is required for glypican-3 modulation of cell survival, Wnt signaling, and gastrulation movements. J Cell Biol. 2003;163(3): 625-635.

51. Hippo Y, Watanabe K, Watanabe A, et al. Identification of soluble NH2terminal fragment of glypican-3 as a serological marker for early-stage hepatocellular carcinoma. Cancer Res. 2004;64(7):2418-2423.

52. Baumhoer D, Tornillo L, Stadlmann S, Roncalli M, Diamantis EK, Terracciano LM. Glypican 3 expression in human nonneoplastic, preneoplastic, and neoplastic tissues: a tissue microarray analysis of 4,387 tissue samples. Am J Clin Pathol. 2008;129(6):899-906.

53. Llovet JM, Chen Y, Wurmbach E, et al. A molecular signature to discriminate dysplastic nodules from early hepatocellular carcinoma in HCV cirrhosis. Gastroenterology. 2006;131(6):1758-1767.

54. Zhu ZW, Friess H, Wang L, et al. Enhanced glypican-3 expression differentiates the majority of hepatocellular carcinomas from benign hepatic disorders. Gut. 2001;48(4):558-564.

55. Hsu HC, Cheng W, Lai PL. Cloning and expression of a developmentally regulated transcript MXR7 in hepatocellular carcinoma: biological significance and temporospatial distribution. Cancer Res. 1997;57(22):5179-5184.

56. Libbrecht L, Severi T, Cassiman D, et al. Glypican-3 expression distinguishes small hepatocellular carcinomas from cirrhosis, dysplastic nodules, and focal nodular hyperplasia-like nodules. Am J Surg Pathol. 2006;30(11):1405-1411.

57. Chen M, Li G, Yan J, et al. Reevaluation of glypican-3 as a serological marker for hepatocellular carcinoma. Clin Chim Acta. 2013;423: 105-111.

58. Qiao SS, Cui ZQ, Gong L, et al. Simultaneous measurements of serum AFP, GPC-3 and HCCR for diagnosing hepatocellular carcinoma. Hepatogastroenterology. 2011;58(110-111):1718-1724.

59. Xu C, Yan Z, Zhou L, Wang Y. A comparison of glypican-3 with $\alpha$-fetoprotein as a serum marker for hepatocellular carcinoma: a metaanalysis. J Cancer Res Clin Oncol. 2013;139(8):1417-1424.

60. Date Y, Kimura A, Kato H, Sasazuki T. DNA typing of the HLA-A gene: population study and identification of four new alleles in Japanese. Tissue Antigens. 1996;47(2):93-101.

61. Ohmori M, Yasunaga S, Maehara Y, Sugimachi K, Sasazuki T. DNA typing of HLA class I (HLA-A) and class II genes (HLA-DR, -DQ and -DP) in Japanese patients with gastric cancer. Tissue Antigens. 1997;50(3):277-282

62. Falk K, Rotzschke O, Stevanovic S, Jung G, Rammensee HG. Allelespecific motifs revealed by sequencing of self-peptides eluted from MHC molecules. Nature. 1991;351:290-296.

63. Maier R, Falk K, Rotzschke O, et al. Peptide motifs of HLA-A3, -A24, and -B7 molecules as determined by pool sequencing. Immunogenetics. 1994;40(4):306-308.
64. Nakatsura T, Komori H, Kubo T, et al. Mouse homologue of a novel human oncofetal antigen, glypican-3, evokes T-cell-mediated tumor rejection without autoimmune reactions in mice. Clin Cancer Res. 2004;10(24):8630-8640.

65. Browning M, Krausa P. Genetic diversity of HLA-A2: evolutionary and functional significance. Immunol Today. 1996;17(4):165-170.

66. Komori H, Nakatsura T, Senju S, et al. Identification of HLA-A2- or HLA-A24-restricted CTL epitopes possibly useful for glypican-3specific immunotherapy of hepatocellular carcinoma. Clin Cancer Res. 2006;12(9):2689-2697.

67. Sawada Y, Yoshikawa T, Nobuoka D, et al. Phase I trial of a glypican-3derived peptide vaccine for advanced hepatocellular carcinoma: immunologic evidence and potential for improving overall survival. Clin Cancer Res. 2012;18(13):3686-3696.

68. Therasse P, Arbuck SG, Eisenhauer EA et al. New guidelines to evaluate the response to treatment in solid tumors. European Organization for Research and Treatment of Cancer, National Cancer Institute of the United States, National Cancer Institute of Canada. J Natl Cancer Inst. 2000;92(3):205-216.

69. Takai H, Kato A, Kinoshita Y, et al. Histopathological analyses of the antitumor activity of anti-glypican-3 antibody (GC33) in human liver cancer xenograft models: the contribution of macrophages. Cancer Biol Ther. 2009;8(10):930-938.

70. Ishiguro T, Sugimoto M, Kinoshita Y, et al. Anti-glypican 3 antibody as a potential antitumor agent for human liver cancer. Cancer Res. 2008;68(23):9832-9838.

71. Nakano K, Orita T, Nezu J, et al. Anti-glypican 3 antibodies cause ADCC against human hepatocellular carcinoma cells. Biochem Biophys Res Commun. 2009;378(2):279-284.

72. Takai H, Kato A, Kato C, et al. The expression profile of glypican-3 and its relation to macrophage population in human hepatocellular carcinoma. Liver Int. 2009;29(7):1056-1064.

73. Nakano K, Ishiguro T, Konishi H, et al. Generation of a humanized anti-glypican 3 antibody by CDR grafting and stability optimization. Anticancer Drugs. 2010;21(10):907-916.

74. Zhu AX, Gold PJ, El-Khoueiry AB, et al. First-in-man Phase I study of GC33, a novel recombinant humanized antibody against glypican-3, in patients with advanced hepatocellular carcinoma. Clin Cancer Res. 2013;19(4):920-928.

75. Feng M, Ho M. Glypican-3 antibodies: a new therapeutic target for liver cancer. FEBS Lett. 2014;588(2):377-382.

76. Kim H, Xu GL, Borczuk AC, et al. The heparan sulfate proteoglycan GPC3 is a potential lung tumor suppressor. Am J Respir Cell Mol Biol. 2003;29(6):694-701.

77. Recio FO, Piver MS, Hempling RE, Driscoll DL. Lack of improved survival plus increase in thromboembolic complications in patients with clear cell carcinoma of the ovary treated with platinum versus nonplatinum-based chemotherapy. Cancer. 1996;78(10):2157-2163.

78. Umezu T, Shibata K, Kajiyama H, Yamamoto E, Nawa A, Kikkawa F. Glypican-3 expression predicts poor clinical outcome of patients with early-stage clear cell carcinoma of the ovary. J Clin Pathol. 2010;63(11):962-966.

79. Suzuki S, Yoshikawa T, Hirosawa T, et al. Glypican-3 could be an effective target for immunotherapy combined with chemotherapy against ovarian clear cell carcinoma. Cancer Sci. 2011;102(9):1622-1629.

80. Sugiyama T, Kamura T, Kigawa J, et al. Clinical characteristics of clear cell carcinoma of the ovary: a distinct histologic type with poor prognosis and resistance to platinum-based chemotherapy. Cancer. 2000;88(11):2584-2589.

81. Suzuki S, Shibata K, Kikkawa F, Nakatsura T. Significant clinical response of progressive recurrent ovarian clear cell carcinoma to glypican-3-derived peptide vaccine therapy: two case reports. Hum Vaccin Immunother. Epub November 19, 2013. 


\section{Publish your work in this journal}

The Journal of Hepatocellular Carcinoma is an international, peerreviewed, open access journal that offers a platform for the dissemination and study of clinical, translational and basic research findings in this rapidly developing field. Development in areas including, but not limited to, epidemiology, vaccination, hepatitis therapy, pathology and

molecular tumor classification and prognostication are all considered for publication. The manuscript management system is completely online and includes a very quick and fair peer-review system, which is all easy to use. Visit http://www.dovepress.com/testimonials.php to read real quotes from published authors.

Submit your manuscript here: http://www.dovepress.com/journal-of-hepatocellular-carcinoma-journal 